Carnets de géographes

GÉOGRAPHES

\title{
Cultures locales et identités : l'exemple des pays du sud sud-ouest landais (France)
}

\section{Marie Pendanx}

\section{(2) OpenEdition}

\section{Journals}

Édition électronique

URL : http://journals.openedition.org/cdg/619

DOI : $10.4000 /$ cdg. 619

ISSN : 2107-7266

Éditeur

UMR 245 - CESSMA

Référence électronique

Marie Pendanx, "Cultures locales et identités : l'exemple des pays du sud sud-ouest landais (France) », Carnets de géographes [En ligne], 9 | 2016, mis en ligne le 30 novembre 2016, consulté le 24 septembre 2020. URL : http://journals.openedition.org/cdg/619; DOI : https://doi.org/10.4000/cdg 619

\section{(c) (i) (3)}

La revue Carnets de géographes est mise à disposition selon les termes de la Licence Creative Commons Attribution - Pas d'Utilisation Commerciale - Pas de Modification 4.0 International. 


\title{
Cultures locales et identités : l'exemple des pays du sud sud-ouest landais (France)
}

\author{
Marie Pendanx
}

Dans le cadre de la mondialisation et dans celui, concomitant, d'une certaine uniformisation culturelle, nous sommes confrontés au paradoxe de l'émergence d'identités et de territoires très localisés (en Aquitaine comme ailleurs), s'appuyant sur des représentations comme sur des pratiques culturelles originales ou, tout au moins, qui s'affichent comme telles.

En quoi consistent exactement ces cultures locales qui souvent se déclinent dans un contexte de recomposition socio-spatiale plus ou moins profonde (périurbanisation, littoralisation des populations ...) ? Dans quelle mesure la confirmation ou l'émergence de ces cultures locales identitaires et territorialisées exerce des incidences sur la citoyenneté, l'aménagement du territoire et le développement territorial ? Comment des univers sociaux arrivent-ils à s'affirmer ? Sur notre terrain d'investigation, l'angle du département des Landes et plus particulièrement sa partie sudouest au contact du Pays-Basque et du Béarn, nous sommes en présence d'une société qui est en renouvellement. Il est par conséquent opportun de s'interroger sur la manière dont se constitue la localité que nous avons choisie comme espace d'étude. Etant confrontés à des objets changeants, chargés d'idéologies, de représentations, nous avons adopté une démarche combinatoire qui s'inscrit au cœur d'une géographie sociale et humaniste. Le travail d'enquête et de recherche réalisé nous permet de montrer que sur cet espace la culture locale est une culture marquée par des apports extérieurs et des singularités propres. L'étude de la vie quotidienne dans notre aire d'investigation sud-landaise a mis en évidence des éléments endogènes constitutifs d'une culture de l'habiter, de l'Ici, de la fête, vivante et populaire. Pour autant, ces spécificités apparentes ne sont le produit que de "branchements" réalisés par des individus de plus en plus mobiles, indépendamment du contexte urbain ou rural. Le local apparait ainsi comme une construction permanente, innovante à travers une logique de "bricolages" identitaires.

\section{Fiche informative \\ Lien électronique si la thèse est disponible en ligne \\ https://halshs.archives-ouvertes.fr/tel-00976337/document}

\section{Discipline}

Géographie

\section{Directeur}

Guy DI MEO

\section{Université}

Université Michel de Montaigne Bordeaux 3

Membres du jury de thèse, soutenue le 04 décembre 2013

- Jean-Pierre AUGUSTIN, Professeur Emérite, Géographie, Université de Bordeaux 3

- Pascal BULEON, Directeur de Recherche au CNRS, Géographie, Directeur de la MRSH de Caen

- Bernard CHERUBINI, Maître de Conférences HDR, Ethnologie, Université de Bordeaux 2 
- Guy DI MEO, Professeur Emérite, Géographie, Université de Bordeaux 3 (Directeur)

- Marie-Claude MAUREL, Directrice d'Etudes, Géographie, Ecole des Hautes Etudes en Sciences Sociales (EHESS Paris) (Rapporteur)

- Jean-Robert PITTE, Professeur, Géographie, Université de Paris 4 - Sorbonne (Rapporteur)

\section{Situation professionnelle actuelle}

Professeur d'Histoire-Géographie remplaçant en collège et lycée

Courriel de l'auteur

mariependanx[at]yahoo.fr 